\title{
The association between COPD and heart failure risk: a review
}

This article was published in the following Dove Press journal:

International Journal of COPD

27 June 2013

Number of times this article has been viewed

\author{
Javier de Miguel Díez' \\ Jorge Chancafe Morgan' \\ Rodrigo Jiménez García ${ }^{2}$ \\ 'Pulmonology Department, Gregorio \\ Maranon University Hospital, \\ Complutense University of Madrid, \\ Madrid, Spain; ${ }^{2}$ Preventive Medicine \\ and Public Health Teaching and \\ Research Unit, Department of Health \\ Sciences, Rey Juan Carlos University, \\ Madrid, Spain
}

Correspondence: Javier de Miguel Díez Pneumology Department, Hospital General Universitario Gregorio Marañon, C/ Doctor Esquerdo, 4628007 Madrid, Spain Tel +34 9l 5868328

$\mathrm{Fax}+34915868325$

Email jmiguel.hgugm@salud.madrid.org

\begin{abstract}
Chronic obstructive pulmonary disease (COPD) is commonly associated with heart failure (HF) in clinical practice since they share the same pathogenic mechanism. Both conditions incur significant morbidity and mortality. Therefore, the prognosis of COPD and HF combined is poorer than for either disease alone. Nevertheless, usually only one of them is diagnosed. An active search for each condition using clinical examination and additional tests including plasma natriuretic peptides, lung function testing, and echocardiography should be obtained. The combination of COPD and HF presents many therapeutic challenges. The beneficial effects of selective $\beta 1$-blockers should not be denied in stable patients who have HF and coexisting COPD. Additionally, statins, angiotensin-converting enzyme inhibitors, and angiotensin-receptor blockers may reduce the morbidity and mortality of COPD patients. Moreover, caution is advised with use of inhaled $\beta 2$-agonists for the treatment of COPD in patients with HF. Finally, noninvasive ventilation, added to conventional therapy, improves the outcome of patients with acute respiratory failure due to hypercapnic exacerbation of COPD or HF in situations of acute pulmonary edema. The establishment of a combined and integrated approach to managing these comorbidities would seem an appropriate strategy. Additional studies providing new data on the pathogenesis and management of patients with COPD and HF are needed, with the purpose of trying to improve quality of life as well as survival of these patients.
\end{abstract}

Keywords: chronic obstructive pulmonary disease, heart failure

\section{Introduction}

Chronic obstructive pulmonary disease (COPD) and heart failure (HF) frequently coexist in clinical practice. ${ }^{1}$ Both conditions share some risk factors including cigarette smoking, advanced age, and systemic inflammation. ${ }^{2}$ The prevalence of COPD among individuals with HF ranges from $20 \%$ to $32 \%$ of cases, and $10 \%$ of hospitalized HF patients also suffer COPD. ${ }^{3}$ From the opposite side, HF is prevalent in more than $20 \%$ of patients with COPD. ${ }^{4,5}$ Moreover, the risk ratio of developing HF among COPD patients is 4.5 times higher than that of control individuals without the disease, after adjusting for age and other cardiovascular risk factors. ${ }^{6}$ The hospital HF adjusted prevalence is three times greater among patients discharged with COPD when compared with patients without this disease. ${ }^{2}$ Nevertheless, we have to take into account that most studies used inappropriate definitions for COPD and HF. They did not consider GOLD's criteria or reproducible echocardiographic parameters. ${ }^{7}$ In a recent study, the authors assessed the prevalence and prognostic implications of the coexistence of COPD and HF using objective measurements. ${ }^{7}$ The prevalence of airway obstruction among chronic HF patients was $37.3 \%$ and the prevalence of ventricular dysfunction among COPD patients was $17 \%{ }^{8}$ 
Also, the presence of ventricular dysfunction in patients with COPD tended to increase the risk of mortality during follow-up, however, the presence of airway obstruction in patients with chronic HF does not seem to influence survival. ${ }^{8}$

The high prevalence of HF in COPD patients is not surprising. We have to bear in mind that these patients have a higher risk of cardiovascular morbidity and mortality which is independent from other factors, such as tobacco use. ${ }^{9,10}$ The forced expiratory volume in the first second $\left(\mathrm{FEV}_{1}\right)$ values appear to be as good a predictor of cardiovascular mortality as cholesterol values. ${ }^{11}$

For all these reasons, it is really important to recognize the coexistence of both processes early. In this article, we review the physiopathology, clinical aspects, diagnosis, and treatment of patients with both conditions, ie, COPD and HF. We therefore performed a bibliographic search in PubMed using the medical subject heading terms "COPD" and "heart failure."

\section{Pathophysiology}

The relationship between COPD and cardiovascular events is not completely clear. Like cardiovascular diseases, there is evidence that suggests that stable COPD is associated with low grade systemic inflammation. ${ }^{12}$ The risk of underlying ischemic heart disease is greater in patients with moderate or severe airflow obstruction and high circulating C-reactive protein (CRP), suggesting a certain influence of this inflammatory marker on cardiac risk. CRP was also found to be correlated with vascular structure and function in COPD patients, although not consistently. ${ }^{13-16}$ In addition, several markers of cardiovascular risk are associated with airflow limitation. ${ }^{13,17-19}$

Moreover, it has also been shown that the association of obstructive sleep apnea (OSA) and COPD, which has been called overlap syndrome, is associated with vascular endothelial dysfunction, elevated inflammatory mediators, and accelerated atherosclerosis. All of these factors are associated with reduced survival. In addition, OSA is considered to lead to insulin resistance, hypertension, and cardiovascular diseases through increased sympathetic activity, inflammation, and oxidative stress. In epidemiologic studies and clinical cohorts, OSA has also been associated with an increased risk of death, mainly because of cardiovascular causes. Indeed, it has been suggested that the number of cardiovascular deaths in patients with untreated overlap syndrome is higher when compared with overlap treated patients, and also higher than those with COPD only. ${ }^{20}$

Inflammation is itself implicated in the pathogenesis of HF. Incidence of this condition was higher among Framingham subjects with elevated CRP and cytokine levels, independently of the status of established risk factors. ${ }^{21}$ A hypothesis to explain the high prevalence of left ventricular systolic dysfunction in COPD patients is that systemic inflammation would accelerate coronary atherosclerosis progression, leading to the development of ischemic heart disease. The high incidence of motor alterations in the left ventricular wall and left ventricular dysfunction that we observe in COPD patients could also explain the relationship between these chronic progressive diseases (Figure 1). ${ }^{22}$ On the other hand, pulmonary hypertension is common in
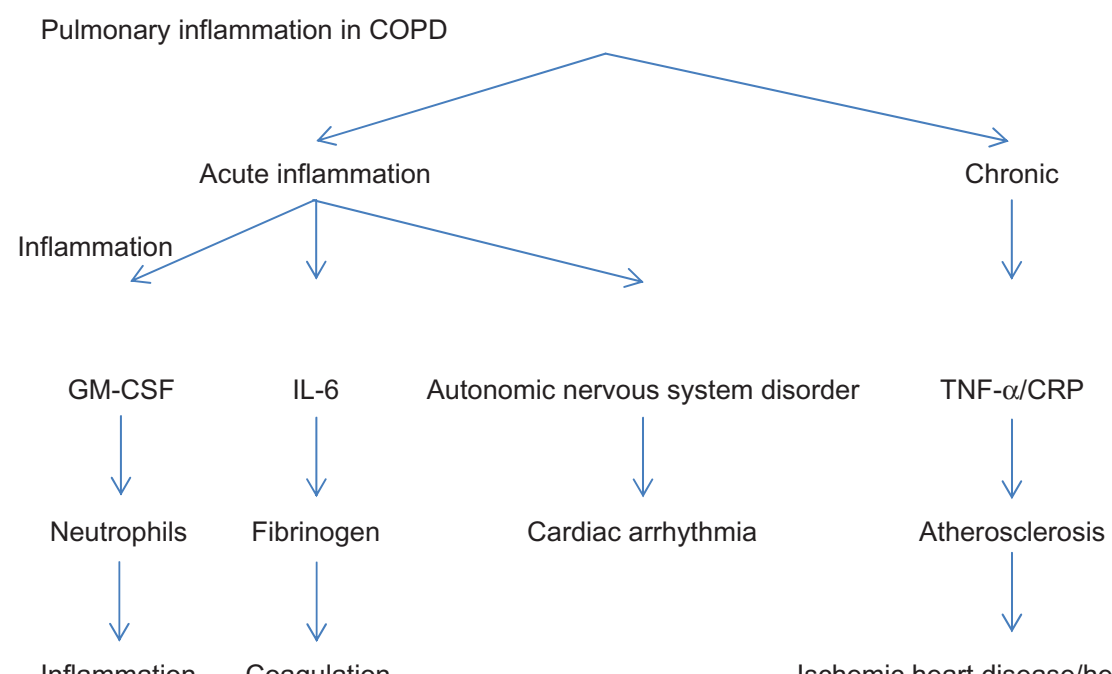

Inflammation Coagulation Ischemic heart disease/heart failure

Figure I Lung inflammation in chronic obstructive pulmonary disease may contribute to the appearance of cardiovascular events.

Abbreviations: COPD, chronic obstructive pulmonary disease; CRP, C-reactive protein; GM-CSF, granulocyte-macrophage colony-stimulating factor; IL-6, interleukin-6; TNF- $\alpha$, tumor necrosis factor- $\alpha$. 
severe COPD and can lead to right HF. In turn, right HF is associated with left $\mathrm{HF}^{23,24}$

Skeletal muscle alterations in patients with COPD and HF include a decrease in muscle mass, size, and diameter. On the fibrillar level, atrophy of type 1 oxidative fibers occurs, and there is a relative increase in type $2 \mathrm{a}$ and $2 \mathrm{~b}$ glycolytic fibers as a result of decreased oxidative enzyme activity and increased glycolytic activity, respectively. ${ }^{25}$

Different techniques have demonstrated the presence of a reduced high energy phosphate concentration at rest, which is more pronounced during exercise. In addition, a faster $\mathrm{pH}$ decline and slower rephosphorylation after exercise are seen in patients with both COPD and $\mathrm{HF}^{26}$

Loss of muscle mass and skeletal muscle atrophy have more serious clinical and therapeutic implications in patients with COPD and HF. Muscular atrophy contributes to muscle fatigue during exercise, which causes these patients to interrupt their exercise in spite of not exhausting their cardiac and respiratory reserves. ${ }^{27} \mathrm{As}$ a result, the maximum oxygen consumption is directly related to skeletal muscle mass in both processes. ${ }^{28}$ The therapeutic interventions that improve pulmonary and left ventricular function in patients with COPD and HF, respectively, do not reverse the muscular atrophy process, and do not, therefore, relieve functional intolerance. The mechanisms involved in muscular atrophy in both diseases are unknown, although they seem to be related to muscular disease, systemic inflammation, and an increase in oxidative stress, which contributes to reducing protein synthesis and accelerating protein degradation. ${ }^{29}$ High circulatory values of proinflammatory cytokines have been found in patients with COPD and HF. These include 8 -isoprostane, which is also found in high concentrations in the pericardial fluid of HF patients. ${ }^{30}$ In summary, COPD patients have an increased risk of developing HF, since both diseases share the same pathogenic mechanism.

\section{Diagnosis}

The symptoms and physical signs of COPD and HF may coexist. ${ }^{31}$ Fatigue and exertional dyspnea are frequent symptoms that are common in both conditions, and they can result in marked activity intolerance. ${ }^{32}$ However, acute onset dyspnea or orthopnea, nocturnal cough, paroxysmal nocturnal dyspnea, ease of fatigue, and reduced exercise tolerance in the absence of infectious exacerbation of COPD gives rise to a diagnosis of HF. The presence of jugular venous distension, ankle edema, and hepatomegaly in COPD should be oriented toward the existence of right ventricular failure. ${ }^{33}$
The electrocardiogram presents a high negative predictive value for the diagnosis of systolic ventricular function when it is normal. However, it is not a specific technique for diagnosing HF when abnormalities are present, as these abnormalities are frequent in patients with COPD and HF. ${ }^{34}$

Chest radiography is not sensitive for detecting the coexistence of COPD and chronic HF, as the cardiothoracic ratio may remain normal as the heart can be long and narrow in a hyperinflated chest, and pulmonary edema can be masked by pulmonary vascular remodeling and radiolucent lung fields. ${ }^{2,33}$ However, it may be useful for detecting other diseases, other than COPD or HF. ${ }^{31}$

In patients with COPD, plasma levels of natriuretic peptides are a fast and sensitive biomarker for diagnosing HF. Both B-type natriuretic peptide (BNP) and N-terminal fragment of B-type natriuretic peptide (NT-proBNP) are produced from a prohormone, proBNP, which is secreted by the myocytes for an increase in atrial and ventricular filling pressure. ${ }^{35}$ A single BNP cutoff point for excluding or detecting HF is $100 \mathrm{pg} / \mathrm{mL}$. Thus, HF is unlikely when BNP levels are below this value. BNP levels ranging from $100 \mathrm{pg} / \mathrm{mL}$ to $500 \mathrm{pg} / \mathrm{mL}$ in COPD patients may be due to cor pulmonale (right ventricular stretch), moderate left ventricular failure, or both. Finally, although not specifically tested in patients with a history of COPD, BNP $>500 \mathrm{pg} / \mathrm{mL}$ is suggested by several authors to indicate acute HF in COPD patients. ${ }^{1,10,12,33}$ Recently, Macchia et al demonstrated that a BNP cutoff point of $160 \mathrm{pg} / \mathrm{mL}$ in COPD patients increases, more than 10 times, the probability of finding a ventricular dysfunction with echocardiography. ${ }^{8}$ For NT-proBNP, a value $<300 \mathrm{pg} / \mathrm{mL}$ excludes $\mathrm{HF}$, and a value $>450 \mathrm{pg} / \mathrm{mL}$ (for patients $<50$ years) or a value $>900 \mathrm{pg} / \mathrm{mL}$ (for those $\geq 50$ years) identifies $\mathrm{HF}$ in patients with previous COPD presenting with acute dyspnea. ${ }^{12}$ For excluding HF, the sensitivity was $94 \%$, while for detecting HF, the specificity was $84 \%$. In COPD patients with previous history of HF, the values of sensitivity and specificity were $97 \%$ and $47 \%$ respectively, and in those without previous COPD these values were $90 \%$ and $90 \%$ respectively. ${ }^{36}$ Regardless, it should be noted that $95 \%-100 \%$ of patients are correctly diagnosed when natriuretic peptides are added to clinical judgment. ${ }^{18,37}$ The recent National Institute for Health and Care Excellence (NICE), guidelines recommend a BNP level $>400 \mathrm{pg} / \mathrm{mL}$ or a NT-proBNP level $>2000 \mathrm{pg} / \mathrm{mL}$ for HF diagnosis. ${ }^{38}$ If doubts exist, cardiac imaging techniques could be applied.

Using an echocardiogram in COPD patients can detect left ventricular dysfunction (diastolic or systolic) 
which is associated with the presence of cardiovascular disease in a high percentage of cases. ${ }^{39}$ In addition, the echocardiographic evaluation of the right ventricle, which determines the systolic pulmonary artery and interventricular septal pressures, is essential to assess the presence of cor pulmonale in COPD patients and to establish their short-term prognosis. ${ }^{40} \mathrm{NICE}$ guidelines recommend an echocardiogram be performed within two weeks in patients with BNP values $>400 \mathrm{pg} / \mathrm{mL}$ or NT-proBNP $>2000 \mathrm{pg} / \mathrm{mL}$, or within 6 weeks in those patients with BNP values between $100 \mathrm{pg} / \mathrm{mL}$ and $400 \mathrm{pg} / \mathrm{mL}$ or NT-proBNP between $400 \mathrm{pg} / \mathrm{mL}$ and $2000 \mathrm{pg} / \mathrm{mL} .{ }^{38}$ If an echocardiogram is normal, HF would be excluded. On the other hand, HF diagnosis should be kept in mind in COPD patients with left ventricular ejection fraction $>40 \%$ and abnormal left ventricular mass, or enlarged left atrium by echocardiography. ${ }^{1}$

Although echocardiography is the reference test for diagnosing HF, it could be limiting in patients with obesity or those with COPD who have a poor echocardiographic window due to pulmonary hyperinflation. ${ }^{41}$ In these cases, evaluating the right ventricle by magnetic resonance imaging (MRI) can be more objective. Apart from providing accurate and reproducible measurements of left ventricular volumes and left ventricular ejection fraction that are not affected by lung hyperinflation, this technique is also valuable in the evaluation of right ventricular volume and function. However, this complementary test has some disadvantages such as the acquisition time, limited availability, and higher costs than echocardiography, which limits its usefulness in clinical practice. Thus, the MRI should be reserved to evaluate left ventricular function in HF patients with technically limited echocardiogram images. ${ }^{2}$

In the resting pulmonary function tests we can see that the obstructed airflow, the destruction of pulmonary tissue in emphysema, and the respiratory muscle weakness in COPD patients, provoke an obstructive type respiratory defect. In turn, HF is accompanied by the development of a restrictive disorder, which is partly due to heart enlargement and pulmonary venous congestion that occurs in this disease. Thus, patients with COPD and HF have combined obstruction and restriction in pulmonary function tests. ${ }^{42}$ However, lung function can improve after treatment of HF. Therefore, in patients with this condition, it is recommended to repeat the spirometry after treatment to make a final diagnosis of COPD. $^{32}$

During exercise, the dynamic hyperinflation caused by the increased residual function capacity, tachypnea caused by COPD, and the increased dead space and $\mathrm{CO}_{2}$ consumption resulting from HF, produce an abnormal ventilation/ perfusion relationship. ${ }^{25}$ In addition, a drop in carbon monoxide diffusing capacity occurs, caused by COPD and HF, limiting the exertion capacity.

Arterial blood gas detects alterations in the gas exchange that occur in COPD and HF patients. During exertion, COPD causes a decrease in $\mathrm{O}_{2}$ arterial pressure $\left(\mathrm{PaO}_{2}\right)$ and an increase in $\mathrm{CO}_{2}$ arterial pressure $\left(\mathrm{PaCO}_{2}\right)$, while the $\mathrm{HF}$ worsens the gas exchange. This favors hypoxemia and increases $\mathrm{PaCO}_{2} \cdot{ }^{43}$

Patients with COPD and HF have significantly impaired cardiopulmonary exercise testing responses. These tests reveal a significantly poorer response in subjects with both diseases by several variables, including peak oxygen consumption, minute ventilation/carbon dioxide production slope, and heart rate recovery at 1 minute. This finding may impact the clinical interpretation of cardiopulmonary exercise testing data in patients with COPD and $\mathrm{HF}^{44}$

In summary, plasma levels of natriuretic peptides can be useful in patients with COPD. These parameters perform better for excluding, rather than for detecting, HF. In case of doubt, cardiac imaging techniques should be used. To investigate simultaneous COPD in HF patients, several pulmonary function tests should be performed.

\section{Therapy}

There are few prospective studies and randomized clinical trials regarding combined treatment for patients with COPD and HF. Most of these results come from retrospective studies, clinical trial subgroup analyses, or meta-analyses with outcomes other than evaluation of treatment for both conditions (combined therapy). We have to consider the fact that the treatment for COPD may have an influence on the clinical course of HF and vice versa. ${ }^{42}$ Now, we offer a brief review of the therapeutic aspects of both.

\section{Pharmacological treatment for HF that influences COPD patient prognosis}

In COPD patients, HF should be treated according to usual $\mathrm{HF}$ guidelines as there is no evidence that $\mathrm{HF}$ should be treated differently in the presence of this respiratory disease. $^{7}$ Although $\beta$-blocker therapy improves symptoms and survival among patients with chronic $\mathrm{HF}$, it is frequently witheld in patients with COPD due to concerns of the diminution of the $\beta_{2}$-agonist bronchodilator effect and the worsening of bronchospasm. ${ }^{45}$ Although a Cochrane meta-analysis concluded that $\beta_{1}$-selective $\beta$ blockade was safe, only $35 \%$ of patients with chronic HF and COPD 
receive $\beta_{2}$-blocker therapy. ${ }^{45}$ Recently, the NICE and the European Society of Cardiology (ESC) guidelines stated that COPD is not a contraindication for the use of $\beta$-blockers. ${ }^{38,46}$ Cardioselectivity is a priority, metoprolol, bisoprolol, and nebivolo are the best candidates.$^{47} \mathrm{~A}$ study has shown that treatment with bisoprolol in patients with COPD and HF decreased $\mathrm{FEV}_{1}$ but without deleterious effects on symptoms and quality of life, and that a selective $\beta_{1}$-blocker is preferable to a nonselective $\beta$-blocker in these patients. ${ }^{34}$ In a study ${ }^{48}$ of patients with moderate to severe airflow obstruction and HF, treatment with bisoprolol and carvedilol was well tolerated and beneficial effects on lung function were seen. However, bisoprolol was superior to carvediol on respiratory parameters. ${ }^{48}$ The benefits of selective $\beta_{1}$-blocker treatment in HF clearly outweigh any potential risk associated with treatment in COPD patients, even in those with severe obstruction. Low dose initially and gradual up-titration is recommended. Mild deterioration in pulmonary function or presence of mild respiratory symptoms should not prompt discontinuation. ${ }^{46}$ Physicians may be even more reluctant to continue $\beta$-blocker therapy during an acute exacerbation of COPD when a patient's respiratory status is most tenuous, although it has been shown that among patients with HF, continuing $\beta_{1}$-selective $\beta$-blockers during hospitalization for COPD appears to be safe. $^{45}$

Treatment with statins, angiotensin-converting enzyme (ACE) inhibitors, and angiotensin-receptor blockers (ARBs) can reduce the morbidity and mortality of COPD patients. ${ }^{49,50}$ Some retrospective studies, such as the one by Mancini et $\mathrm{al}^{49}$ have shown a reduced risk of hospitalization in COPD patients treated with statins who also received treatment with ACE inhibitors and/or ARBs. In fact, in patients with absolute contraindications for $\beta$-blockers, the association of ACE inhibitors and ARBs could be a treatment option for increasing survival, as shown in a meta-analysis that has evaluated this topic. ${ }^{49}$ Additionally, Mortensen et al have also reported that the use of statins and ACE inhibitors prior to hospital admission is associated with a decreased mortality in subjects hospitalized for COPD exacerbation. ${ }^{50}$ Recently, in a prospective study by Bartziokas et al, the use of statins was associated with a low risk of COPD exacerbation and more severe COPD. ${ }^{51}$ Nonetheless, results from these studies should be cautiously interpreted. We think that new controlled studies to establish their real usefulness are needed. In the meantime, the use of these medications should only be recommended when COPD patients have an associated condition with clear indication. ${ }^{52}$
The use of diuretics is another important aspect that must be evaluated in these patients, given that high doses of loop diuretics can produce metabolic alkalosis, with the presence of hypoventilation as a compensatory mechanism, which in turn could worsen hypercapnia. ${ }^{53,54}$ In addition, although large prospective studies are not available, the use of high doses of diuretics in HF patients is associated with a high risk of kidney dysfunction, morbidity, and mortality. ${ }^{55}$

A recent study ${ }^{56}$ that assessed the pharmacologic treatment of patients with COPD and HF showed that only $22 \%$ of patients with both conditions were prescribed $\beta$-blockers, as opposed to $81 \%$ of those without COPD. This contrasted markedly with the prescription of ACE inhibitors and ARBs, where no significant difference was noted between these two groups. Most COPD patients were prescribed aldosterone antagonists while a few were prescribed loop diuretics. ${ }^{56}$

\section{Pharmacological treatment of COPD in patients with HF}

COPD should be treated according to clinical guidelines in patients with $\mathrm{HF}$ as there is no direct evidence that this respiratory disease should be treated differently in the presence of HF. ${ }^{7}$ This statement is based on findings from large long-term studies in patients with HF and comorbid COPD. ${ }^{57-59}$

Inhaled $\beta_{2}$-agonists are part of the mainstay of the COPD pharmacological treatment. However, they can induce adverse cardiac effects in COPD patients with pre-existing cardiovascular disease, especially in those with coexistent HF. An observational study found an increased risk of death and hospital admission among patients with HF treated with inhaled $\beta$-agonists, ${ }^{60}$ possibly indicating a need for close follow-up of patients with severe HF who are on this treatment for COPD. Oral $\beta_{2}$-agonists should be avoided, and both the dose and frequency of nebulized therapy should be minimized. Patients with HF and concomitant COPD who require a regular long-acting inhaled bronchodilator, should start treatment with a long-acting antimuscarinic rather than long-acting $\beta_{2}$-agonists. ${ }^{47}$ However, in a recent study where patients with COPD and HF were assessed, $\beta_{2}$-agonists were the most frequent therapy for COPD, followed by inhaled corticosteroids and anti-muscarinic drugs. ${ }^{56}$

Furthermore, the use of corticosteroids can increase the risk of hydrosaline retention in HF patients. There are studies that show that COPD patients who received high doses of corticosteroids (doses of prednisone above $20 \mathrm{mg} /$ day) had a higher risk of presenting with an episode of decompensated HF than those who received these drugs in lower doses. ${ }^{61}$ 
Inhaled corticosteroids have a lower risk for side effects than oral administration, they can be administered if indicated according to clinical guidelines.

Finally, methylxanthines are in decreasing use, do not seem to be a good alternative treatment for patients with COPD and HF. They carry an increased risk for arrhythmias. ${ }^{42}$

\section{Noninvasive ventilation}

\section{in patients with COPD and HF}

Noninvasive ventilation (NIV), added to conventional therapy, improves the outcome of patients with acute respiratory failure due to hypercapnic exacerbation of COPD or heart failure in situations of acute pulmonary edema. NIV improves gas exchange and symptoms in patients with COPD, reducing the need for endotracheal intubation, hospital mortality, and hospital stay when compared with conventional oxygen therapy. NIV may also avoid reintubation and may decrease the length of invasive mechanical ventilation. In acute cardiogenic pulmonary edema, NIV accelerates the remission of symptoms and the normalization of blood gas parameters, reduces the need for endotracheal intubation, and is associated with a trend toward lower mortality. The ventilation modality used in acute pulmonary edema does not affect patient prognosis. ${ }^{62}$

In patients with cor pulmonale secondary to a chronic pulmonary disease like COPD, the use of Biphasic Positive Airway Pressure (BiPAP), can improve the right ventricular function and decrease plasma levels of natriuretic peptides. ${ }^{63}$ Furthermore, recent studies have concluded that administering this treatment method can play an important role for HF patients with associated muscle fatigue and hypercapnia. ${ }^{64,65}$

In summary, the combination of COPD and HF presents many therapeutic challenges. The beneficial effects of cardioselective $\beta 1$-blockers should not be denied in stable patients who have HF and coexistent COPD. Statins, ACE inhibitors, and ARBs may reduce the morbidity and mortality of COPD patients. Moreover, caution is advised with use of inhaled $\beta 2$-agonists for the treatment of COPD in patients with HF. NIV, when added to conventional therapy, improves the outcome of patients with acute respiratory failure due to hypercapnic exacerbation of COPD or heart failure in situations of acute pulmonary edema. The establishment of a combined and integrated approach to managing these comorbidities would seem an appropriate strategy.

\section{Conclusion}

COPD is commonly associated with HF in clinical practice. Both conditions incur significant morbidity and mortality.
Clinicians attending these patients should perform an integrated approach to objectively identify both diseases at an early stage, and to optimize control of respiratory and cardiovascular conditions. This will result in a reduction in the morbidity and mortality of these patients. Additional studies providing new data on the pathogenesis and management of patients with COPD and $\mathrm{HF}$ are needed, with the purpose of trying to improve quality of life as well as survival of these patients.

\section{Disclosure}

The authors declare no conflicts of interest in this work.

\section{References}

1. Le Jemtel TH, Padeletti M, Jelic S. Diagnostic and therapeutic challenges in patients with coexistent chronic obstructive pulmonary disease and chronic heart failure. $J$ Am Coll Cardiol. 2007;49(2): 171-180.

2. Hawkins NM, Petrie MC, Jhund PS, Chalmers GW, Dunn FG, McMurray JV. Heart failure and chronic obstructive pulmonary disease: diagnosis pitfalls and epidemiology. Eur J Heart Fail. 2009;11(2): $130-139$.

3. Ni H, Nauman D, Hershberger RE. Managed care and outcomes of hospitalization among elderly patients with congestive heart failure. Arch Intern Med. 1998;158(11):1231-1236.

4. Lainscak M, Hodoscek LM, Düngen HD, et al. The burden of chronic obstructive pulmonary disease in patients hospitalized with heart failure. Wien Klin Wochenschr. 2009;121(9-10):309-313.

5. Ukena C, Mahfoud F, Kindermann M, et al. The cardiopulmonary continuum systemic inflammation as 'common soil' of heart and lung disease. Int J Cardiol. 2010;145(2):172-176.

6. Curkendall SM, DeLuise C, Jones JK. Cardiovascular disease in patients with chronic obstructive pulmonary disease, Saskatchewan Canada cardiovascular disease in COPD patients. Ann Epidemiol. 2006; 16(1):63-70.

7. Global Initiative for Chronic Obstructive Lung Disease. Global Strategy for Diagnosis, Management, and Prevention of COPD. Updated Feb 2013. Available from: http://www.goldcopd.org/Guidelines/ guidelines-resources.html. Accessed April 26, 2013.

8. Macchia A, Rodríguez Moncalvo JJ, et al. Unrecognised ventricular dysfunction in COPD. Eur Respir J. 2012;39(1):51-58.

9. De Blois J, Simard S, Atar D, Agewall S; Norwegian Heart Failure Registry. COPD predicts mortality in HF: the Norwegian Heart Failure Registry. J Card Fail. 2010;16(3):225-229.

10. van der Molen T. Co-morbidities of COPD in primary care: frequency, relation to COPD, and treatment consequences. Prim Care Respir J. 2010;19(4):326-334.

11. Hole DJ, Watt GC, Davey-Smith G, Hart CL, Gillis CR, Hawthorne VM. Impaired lung function and mortality risk in men and women: findings from the Renfrew and Paisley prospective population study. BMJ. 1996; 313(7059):711-715.

12. Hannink JDC, Van Helvoort HAC, Dekhuijzen PNR, Heijdra YF. Heart failure and COPD: partners in crime? Respirology. 2010; 15(6):895-901.

13. Iwamoto H, Yokoyama A, Kitahara Y, et al. Airflow limitation in smokers is associated with subclinical atherosclerosis. Am J Respir Crit Care Med. 2009;179(1):35-40.

14. Eickhoff P, Valipour A, Kiss D, et al. Determinants of systemic vascular function in patients with stable chronic obstructive pulmonary disease. Am J Respir Crit Care Med. 2008;178(12):1211-1218.

15. Mills NL, Miller JJ, Anand A, et al. Increased arterial stiffnes in patients with chronic obstructive pulmonary disease: a mechanism for increased cardiovascular risk. Thorax. 2008;63(4):306-311. 
16. McAllister DA, Maclay JD, Mills NL, et al. Arterial stiffness is independently associated with emphysema severity in patients with chronic obstructive pulmonary disease. Am J Respir Crit Care Med. 2007;176(12):1208-1214.

17. Sin DD, Man SF. Why are patients with chronic obstructive pulmonary disease at increased risk of cardiovascular diseases? The potential role of systemic inflammation in chronic obstructive pulmonary disease. Circulation. 2003;107(11):1514-1519.

18. Sabit R, Bolton CE, Edwards PH, et al. Arterial stiffness and osteoporosis in chronic obstructive pulmonary disease. Am J Respir Crit Care Med. 2007;175(12):1259-1265.

19. Zureik M, Benetos A, Neukirch C, et al. Reduced pulmonary function is associated with central arterial stiffness in men. Am J Respir Crit Care Med. 2001;164(12):2181-2185.

20. Marin JM, Soriano JB, Carrizo SJ, Boldova A, Celli BR. Outcomes in patients with chronic obstructive pulmonary disease and obstructive sleep apnea. The overlap syndrome. Am J Respir Crit Care Med. 2010; 182(3):325-331.

21. Vasan RS, Sullivan LM, Roubenoff R, Dinarello CA, Harris T, Benjamin EJ. Inflammatory markers and risk of heart failure in elderly subjects without prior myocardial infarction: the Framingham Heart Study. Circulation. 2003;107(11):1486-1491.

22. Steele P, Ellis JH, van Dyke D, Sutton F, Creagh E, Davies H. Left ventricular ejection fraction in severe chronic obstructive airways disease. Am J Med. 1975;59(1):21-28.

23. Boussuges A, Pinet C, Molenat F, et al. Left atrial and ventricular filling in chronic obstructive pulmonary disease. An echocardiographic and Doppler study. Am J Respir Crit Care Med. 2000;162(2 Pt 1): 670-675.

24. Louie EK, Rich S, Levitsky S, Brundage BH. Doppler echocardiographic demonstration of the differential effects of right ventricular pressure and volume overload on left ventricular geometry and filling. J Am Coll Cardiol. 1992;19(1):84-90.

25. Gosker HR, Lencer NH, Franssen FM, van der Vusse GJ, Wouters EF, Schols AM. Striking similarities in systemic factors contributing to decreased exercise capacity in patients with severe chronic heart failure or COPD. Chest. 2003;123(5): 1416-1424.

26. Gosker HR, Wouters EF, van der Vusse GJ, Schols AM. Skeletal muscle dysfunction in chronic obstructive pulmonary disease and chronic heart failure: underlying mechanisms and therapy perspectives. Am J Clin Nutr. 2000;71(5):1033-1047.

27. Jondeau G, Katz SD, Zohman L. Active skeletal muscle mass and cardiopulmonary reserve. Failure to attain peak aerobic capacity during maximal bicycle exercise in patients with severe congestive heart failure. Circulation. 1992;86(5):1351-1356.

28. Harrington D, Anker SD, Chua TP. Skeletal muscle function and its relation to exercise tolerance in chronic heart failure. J Am Coll Cardiol. 1997;30(7):1758-1764.

29. Jackman RW, Kandarian SC. The molecular basis of skeletal muscle atrophy. Am J Physiol Cell Physiol. 2004;287(4):C834-C843.

30. Gan WQ, Man SF, Senthilselvan A, Sin DD. Association between chronic obstructive pulmonary disease and systemic inflammation: a systematic review and a meta-analysis. Thorax. 2004;59(7):574-580.

31. Stevenson L, Perloff J. The limited reliability of physical signs for estimating hemodynamics in chronic heart failure. JAMA. 1989; 261(6):884-888.

32. Zeng Q, Jiang S. Update in diagnosis and therapy of coexistent chronic obstructive pulmonary disease and chronic heart failure. J Thorac Dis. 2012;4(3):310-315.

33. Chhabra SK, Gupta M. Coexistent chronic obstructive pulmonary diseaseheart failure: mechanisms, diagnostic and therapeutic dilemmas. Indian J Chest Dis Allied Sci. 2010;52(4):225-238.

34. Davie AP, McMurray JJ. Value of ECGs in identifying heart failure due to left ventricular systolic dysfunction. BMJ. 1996;313(7052):300-301.

35. Boomama F, van der Meiracker AH. Plasma A- and B-type natriuretic peptides: physiology, methodology and clinical use. Cardiovasc Res. 2001;51(3):442-449.
36. Tung RH, Camargo CA Jr, Krauser D, et al. Amino-terminal pro-brain natriuretic peptide for the diagnosis of acute heart failure in patients with previous obstructive airway disease. Ann Emerg Med. 2006; 48(1): 66-74.

37. McCullough PA, Hollander JE, Nowak RM, et al. Uncovering heart failure in patients with a history of pulmonary disease: rationale for the early use of B-type natriuretic peptide in the emergency department. Acad Emerg Med. 2003;10(3):198-204.

38. Al-Mohammad A, Mant J. The diagnosis and management of chronic heart failure: review following the publication of the NICE guidelines. Heart. 2011;97(5):411-416.

39. Render ML, Weinstein AS, Blaustein AS. Left ventricular dysfunction in deteriorating patients with chronic obstructive pulmonary disease. Chest. 1995;107(1):162-168.

40. Biernacki W, Flenley DC, Muir AL, MacNee W. Pulmonary hypertension and right ventricular function in patients with COPD. Chest. 1988;94(6):1169-1175.

41. Devereaux RB, Liebson PR, Horan MJ. Recommendations concerning use of echocardiography in hypertension and general population research. Hypertension. 1987;9(2 Pt 2):II97-II104.

42. Villar Alvarez F, Méndez Bailón M, de Miguel Díez J. Chronic obstructive pulmonary disease and heart failure. Arch Bronconeumol. 2009;45(8):387-393.

43. Navarro Esteva J, Alonso B. Insuficiencia cardiaca y enfermedad pulmonar obstructiva crónica. [Heart failure and chronic obstructive pulmonary disease]. Arch Med. 2005;1. Available from: http://www. archivosdemedicina.com. Accessed February 28, 2013. Spanish.

44. Guazzi M, Myers J, Vicenzi M, et al. Cardiopulmonary exercise testing characteristics in heart failure patients with and without concomitant chronic obstructive pulmonary disease. Am Heart J. 2010;160(5):900-905.

45. Stefan MS, Rothberg MB, Priya A, Pekow PS, Au DH, Lindenauer PK. Association between $\beta$-blocker therapy and outcomes in patients hospitalized with acute exacerbations of chronic obstructive lung disease with underlying ischaemic heart disease, heart failure or hypertension. Thorax. 2012;67(11):977-984.

46. Dickstein K, Cohen-Solal A, Filippatos G, et al. Guidelines for the diagnosis and treatment of acute and chronic heart failure 2008: the task force for the diagnosis and treatment of acute and chronic heart failure 2008 of the European Society of Cardiology. Developed in collaboration with the Heart Failure Association of the ESC (HFA) and endorsed by the European Society of Intensive Care Medicine (ESICM). Eur Heart J. 2008;29(19):2388-2442.

47. Hawkins NM, Petrie MC, MacDonald MR, et al. Heart failure and chronic obstructive pulmonary disease. The quandary of beta-blockers and beta-agonists. J Am Coll Cardiol. 2011;57(21): 2127-2138.

48. Lainscak M, Podbregar M, Kovacic D, Roman J, von Haehling S. Differences between bisoprolol and carvedilol in patients with chronic heart failure and chronic obstructive pulmonary disease: a randomized trial. Respir Med. 2011;105(Suppl 1):S44-S49.

49. Mancini GB. Reduction of morbidity and mortality by statins, angiotensin-converting enzyme inhibitors, and angiotensin receptor blockers in patients with chronic obstructive pulmonary disease. $J \mathrm{Am}$ Coll Cardiol. 2006;47(12):2554-2560.

50. Mortensen EM, Copeland LA, Pugh MJ, et al. Impact of statins and ACE inhibitors on mortality after COPD exacerbations. Respir Res. 2009;10:45

51. Bartziokas K, Papaioannou AI, Minas M, Kostikas K, Banya W, Daniil ZD, et al. Statins and outcome after hospitalization for COPD exacerbation: a prospective study. Pulm Pharmacol Ther. 2011; 24(5):625-631.

52. De Miguel Díez J, Morán Caicedo L, Rodríguez Rodríguez P, Juarez Morales MC, Puente Maestu L, Alvarez-Sala Walther L. La enfermedad pulmonar obstructiva crónica como factor de riesgo cardiovascular [COPD as a cardiovascular risk]. Aten Primaria. Epub March 5, 2012. Spanish. 
53. Aronow WS. Treatment of heart failure in older persons. Dilemmas with coexisting conditions: diabetes mellitus, chronic obstructive pulmonary disease, and arthritis. Congest Heart Fail. 2003;9(3):142-147.

54. Rutten FH, Cramer MJ, Lammers JW, Grobbee DE, Hoes AW. Heart failure and chronic obstructive pulmonary disease: an ignored combination? Eur J Heart Fail. 2006;8(7):706-711.

55. Eshaghian M. Relation of loop diuretic dose to mortality in advanced heart failure. Am J Cardiol. 2006;97(12):1759-1764.

56. O'Kelly N, Robertson W, Smith J, Dexter J, Carroll-Hawkins C, Ghosh S. Short-term outcomes in heart failure patients with chronic obstructive pulmonary disease in the community. World J Cardiol. 2012;4(3):66-71.

57. Calverley PM, Anderson JA, Celli B, et al; TORCH investigators. Salmeterol and fluticasone propionate and survival in chronic obstructive pulmonary disease. N Engl J Med. 2007;356(8):775-789.

58. Tashkin DP, Celli B, Senn S, et al; UPLIFT Study Investigators. A 4-year trial of tiotropium in chronic obstructive pulmonary disease. $N$ Engl J Med. 2008;359(15):1543-1554.

59. Calverley PM, Anderson JA, Celli B, et al; TORCH Investigators. Cardiovascular events in patients with COPD: TORCH study results. Thorax. 2010;65(8):719-725.

60. Au DH, Udris EM, Fan VS, Curtis JR, McDonell MB, Fihn SD. Risk of mortality and heart failure exacerbations associated with inhaled beta-adrenoceptor agonists among patients with known left ventricular systolic dysfunction. Chest. 2003;123(6):1964-1969.
61. Souverein DC. Use of oral glucocorticoids and risk of cardiovascular and cerebrovascular disease in a population based case-control study. Heart. 2004;90(8):859-865.

62. Rialp Cervera G, Del Castillo Blanco A, Pérez Aizcorreta O, Parra Morais L; por el GT-IRA de la SEMICYUC. Noninvasive mechanical ventilation in chronic obstructive pulmonary disease and in acute cardiogenic pulmonary edema. Med Intensiva. Epub November 15, 2012. Spanish.

63. Thorens JB, Ritz M, Reynard C, et al. Haemodynamic and endocrinological effects of noninvasive mechanical ventilation in respiratory failure. Eur Respir J. 1997;10(11):2553-2559.

64. Masip J, Betbesé AJ, Páez J, Vecilla F, Cañizares R, Padró J, et al. Non-invasive pressure support ventilation versus conventional oxygen therapy in acute cardiogenic pulmonary oedema: a randomised trial. Lancet. 2000;356(9248):2126-2132.

65. Resterholtz T, Kempf J, Berton C, et al. Noninvasive pressure support ventilation (NIPSV) with face mask in patients with acute cardiogenic pulmonary edema (ACPE). Intensive Care Med. 1999;25(1):21-28.
International Journal of COPD

\section{Publish your work in this journal}

The International Journal of COPD is an international, peer-reviewed journal of therapeutics and pharmacology focusing on concise rapid reporting of clinical studies and reviews in COPD. Special focus is given to the pathophysiological processes underlying the disease, intervention programs, patient focused education, and self management protocols.

\section{Dovepress}

This journal is indexed on PubMed Central, MedLine and CAS. The manuscript management system is completely online and includes a very quick and fair peer-review system, which is all easy to use. Visit http://www.dovepress.com/testimonials.php to read real quotes from published authors. 